\title{
Homonegativity Experienced over the Life Course by Young Black Gay, Bisexual and Other Men Who Have Sex with Men (YB-GBMSM) Living with HIV in Atlanta, Georgia
}

\author{
Shamia Moore ${ }^{1}$ Marxavian Jones ${ }^{1}$. Justin C. Smith ${ }^{2}$. Jasper Hood ${ }^{1}$. Gary W. Harper ${ }^{3}$. \\ Andres Camacho-Gonzalez ${ }^{4}$. Carlos del Rio ${ }^{1,5} \cdot$ Sophia A. Hussen $^{1,5}$
}

Published online: 28 August 2019

๑) Springer Science+Business Media, LLC, part of Springer Nature 2019

\begin{abstract}
Minority stress theory posits that homonegativity—whether experienced, anticipated, or internalized—adversely impacts health. We conducted qualitative interviews with 28 YB-GBMSM living with HIV to explore manifestations of homonegativity over the life course. Thematic analysis identified patterns in the ways that homonegativity was discussed at different points in participants' lives. Stifling, and sometimes traumatic, familial and religious environments led to experienced homonegativity early in life. These experiences led to anticipated and internalized homonegativity, which in turn shaped sexual identity formation processes in adolescence and into young adulthood. Ultimately, many participants distanced themselves from home environments, seeking and often finding extrafamilial support. Most participants eventually reached self-acceptance of both their sexuality and HIV status. In conclusion, experienced, anticipated and internalized homonegativity were pervasive as YB-GBMSM navigated family and religious environments over the life course. Future interventions should work with youth, families, and churches to prevent these harmful experiences.
\end{abstract}

Keywords Sexual minority health $\cdot$ HIV/AIDS

\section{Resumen}

La teoría del estrés de las minorías postula que la homonegatividad, ya sea experimentada, anticipada o internalizada, afecta negativamente a la salud. Realizamos entrevistas cualitativas con 28 YB-GBMSM que viven con el VIH para explorar las manifestaciones de homonegatividad a lo largo del curso de la vida. El análisis temático identificó patrones en las formas en que se discutió la homonegatividad en diferentes puntos de la vida de los participantes. Los ambientes sofocantes, a veces traumáticos, familiares y religiosos causaron a una homonegatividad experimentada en la vida temprana. Estas experiencias causaron a una homonegatividad interna e anticipada, que a su vez dio forma a los procesos de formación de la identidad sexual en la adolescencia y en la edad adulta temprana. En última instancia, muchos participantes se distanciaron de los entornos del hogar, buscando y con frecuencia encontrando apoyo extrafamiliar. La mayoría de los participantes finalmente llegaron a la autoaceptación de su sexualidad y su estado de VIH. En conclusión, la homonegatividad experimentada, anticipada e internalizada fue generalizada en los entornos familiares y religiosos de YB-GBMSM durante el curso de la vida. Las intervenciones futuras deberían trabajar con los jóvenes, las familias y las iglesias para prevenir estas experiencias dañinas.

Sophia A. Hussen

Sophia.ahmed.hussen@emory.edu

1 Hubert Department of Global Health, Emory University Rollins School of Public Health, Atlanta, Georgia

2 Department of Behavioral Sciences and Health Education, Emory University Rollins School of Public Health, Atlanta, Georgia
3 Department of Health Behavior and Health Education, University of Michigan School of Public Health, Ann Arbor, MI, USA

4 Division of Infectious Diseases, Department of Pediatrics, Emory University School of Medicine, Atlanta, Georgia

5 Division of Infectious Diseases, Department of Medicine, Emory University School of Medicine, Atlanta, Georgia 


\section{Introduction}

An estimated 1.1 million people are currently living with HIV in the United States (US), approximately $70 \%$ of whom are gay, bisexual and other men who have sex with men (GBMSM). Among US MSM, incidence and prevalence vary widely across age and racial/ethnic groups [1]. Black GBMSM, particularly young Black GBMSM (YBGBMSM) bear a disproportionate burden of HIV relative to other racial groups; prevalence among YB-GBMSM is estimated at $26 \%$ (vs. 3\% among their white counterparts) [2]. There are also significant geographic disparities in the US epidemic, with the Southern states being disproportionately impacted [3-5]. Although the Southern US is only home to $38 \%$ of the country's population, over $50 \%$ of new cases of HIV/AIDS were diagnosed in the South in 2016 [4]. Fifty percent of people who are unaware they are living with HIV live in the South, and over 50\% of the HIV-related deaths occur within this region [3].

Several factors contribute to HIV-related disparities in the South [5, 6]. Social conservatism, including opposition to same-sex sexual behavior and marriage, is most prevalent in the South-informally referred to as the "Bible belt" due to the pervasiveness of conservative religious and political views [6]. These conservative ideologies have been associated with increased HIV stigma, and often work to decrease the effectiveness of HIV prevention and treatment efforts $[5,6]$. Poverty also plays a role in the Southern HIV epidemic; eight of the ten poorest US states (as measured by lowest median income) are Southern [6]. Poverty may lead to HIV risk in a multitude of ways including direct associations - in one recent study based in the US South, poverty at the county-level was correlated with HIV prevalence [7]. Finally, policies related to health insurance and delivery of healthcare services contribute to regional disparities as well. People living in the South are less likely to have health insurance [5, 6], due in part to lack of Medicaid expansion in the majority of Southern states even after the passage of the Affordable Care Act. Additionally, analyses show that the Ryan White HIV/AIDS program, which provides care to uninsured people living with HIV (PLWH), gives less funding per person to states in the South [8]. Thus, for many PLWH in this region, limited access to financial resources is often a barrier to seeking quality healthcare services, which in turn are not always readily available.

It is therefore well established that HIV disproportionately affects Southern populations, and that YB-GBMSM are at especially high risk. However, little work has specifically examined the ways in which different Southern cultural and political environments may impact HIV risk for YB-GBMSM over the life course. Several studies have linked conservative cultural climates to HIV risk, but the intrapersonal pathways between cultural conservatism and HIV risk are understudied. We hypothesize that homonegativity, defined as negative societal attitudes about homosexuality and same-sex sexual behaviors, is a key mediator of these pathways [9].

The construct of homonegativity is outlined in Meyer's minority stress theory, which posits that sexual prejudice is stressful to sexual minorities, leading to negative effects on physical and mental health [9]. Meyer specifically outlines three types of minority stress: (1) external stressful events (e.g., experienced discrimination); (2) stress related to the anticipation of discrimination; and (3) internalization of negative societal attitudes, or internalized homonegativity. Internalized homonegativity may be experienced throughout the life course of LGBTQ individuals, and can persist even after achieving some level of identity acceptance [9]. Associations between internalized homonegativity, low self-esteem and mental health outcomes (e.g., anxiety and depression) are well documented [10-13]. Of note, several studies suggest that internalized homonegativity is higher among sexual minority youth than older individuals [10-13], suggesting that YB-GBMSM would be at particularly high risk.

Prior research on homonegativity among Black GBMSM has primarily focused on internalized homonegativity and is generally not specific to younger subsets of this population. Of note, studies in primarily white samples may not reflect the lived experiences of YB-GBMSM, as researchers have shown marked differences in amount and characterizations of internalized homonegativity across racial groups [13-15]. Studies specific to Black GBMSM have identified higher self-perceived masculinity and increased levels of religiosity as risk factors for internalized homonegativity [13]. Conversely, culturally-specific forms of resilience can also be protective against internalized homonegativity in Black GBMSM [13].

Prior research also points to experienced and internalized homonegativity as possible predictors of elevated HIV risk among Black GBMSM [11, 13, 16-18]. A study of YBGBMSM in Mississippi found that anti-gay cultural norms served as a barrier to safe sex practices [19]. Another investigation of experiences of homophobic events among Black MSM found that experienced homophobia was a predictor of condomless anal sex within this population [17]. Improved understanding of the manifestations of homonegativity may therefore serve as a powerful tool to mitigate these processes and decrease HIV risk among YB-GBMSM.

Similar to the rest of the South, the state of Georgia is characterized by low socioeconomic status and poor health outcomes [4]. Of note, however, the cultural context of Atlanta, Georgia's capital city, is somewhat distinct from its Deep South surroundings. Atlanta is colloquially known as the "Black Gay Mecca" due to the presence of a large and 
visible Black lesbian, gay, bisexual, transgender, and queer (LGBTQ) community, many of whom have migrated from other parts of the South [20]. While many consider Atlanta to represent the pinnacle of Black gay life and culture, it is also an HIV epicenter, where the majority of PLWH are Black GBMSM [21, 22]. Given the unique positioning of Atlanta as a "Black Gay Mecca" and HIV epicenter that is situated within, yet somewhat unique compared to the rest of the Southern US, we sought to qualitatively explore the manifestations of homonegativity over the life course in a group of YB-GBMSM living with HIV in Atlanta.

\section{Methods}

\section{Context}

This analysis is derived from a larger intervention development study focused on social capital and engagement in care among YB-GBMSM living with HIV in Atlanta, Georgia [23]. We conducted in-depth interviews (IDIs) with 28 YB-GBMSM living with HIV between May and October of 2017. The semi-structured IDI guide was divided into five domains: (1) Early Life Experiences, (2) Social Network Composition, (3) HIV Stigma, Disclosure, and Gay Identity, (4) Using Social Capital, and (5) Reciprocity. The first three domains elicited information on Meyer's constructs of anticipated, experienced, and internalized homonegativity and thus comprised the focus of the current secondary analysis. Our study was conducted in collaboration with a youth advisory board (YAB) comprised of nine YB-GBMSM living with HIV. The YAB provided input in development of the interview guide, recruitment of participants, and conducting of interviews. The study was approved by the Emory University Institutional Review Board and the Grady Research Oversight Committee.

\section{Participants}

Eligibility criteria included, by self-report: age between 18 and 29 years, Black/African-American race, male gender, HIV-positive serostatus, and any history of sex with men. Participants were identified through an HIV clinic, partnering community-based organizations, and personal referrals from the YAB and study team.

\section{Procedures}

All interviewers were trained in qualitative research methods. The majority of IDIs were conducted by two members of the research team who self-identified as Black and gay (one male and one female). Members of the YAB also underwent training in qualitative interviewing and helped to conduct some IDIs (accompanied by research team members). All IDIs were conducted in either a private room within a clinic building, or an alternative location that was more accessible to the participant. Before each IDI, participants completed a brief demographic questionnaire. On average, IDIs lasted one and a half to two hours. IDIs were recorded digitally and transcribed verbatim by a professional transcriptionist. Upon completion of the IDI, participants received written information about the study and a $\$ 50$ gift card as a token of appreciation for participating. After each interview, members of the research team convened to debrief; salient emerging themes were added to the interview guide in an iterative fashion. Interviews were conducted until thematic saturation was reached.

\section{Thematic Analysis}

Transcripts were imported into MAXQDA 12 (VERBI software, Berlin, Germany), a qualitative data management program, for coding and thematic analysis. The research team began the analytic process by developing a codebook, using a combination of structural (deductive) codes derived from the interview guide and guiding theoretical framework, and inductive codes derived from the data. The codebook was amended repeatedly through an iterative process, which consisted of reading transcripts, identifying recurring themes, discussing codes, and refining definitions. Next, research staff wrote thick descriptions of each theme-which were extensive memos of each code to explain depth, breadth, context, nuance, as well as to explain relationships between codes [24]. Finally, we compared participant cases and analyzed emergent patterns in the data. Thematic saturation was determined through a group-level process of assessing how often themes occurred across the dataset and how completely each theme could be understood based on the data presented. The data met our criteria for saturation on the concept of homonegativity, in that the additional gathering of data ceased to spark new theoretical insights or reveal new properties of this concept [25].

\section{Results}

\section{Sample Description}

We interviewed 28 YB-GBMSM between the ages of 18 and 29 (Table 1). The average age of participants was 24.3 years (standard deviation $=2.7$ years). All participants had at least a high school diploma equivalent or a trade certification, and most had some postsecondary education as 
well. The majority of participants were raised in the South, but only eight participants were raised within metropolitan Atlanta. Fourteen participants were from other parts of the South, four participants were from the Northeast, and two participants were from the Midwest. Nine participants described their hometowns as small or rural during their interviews.

We found that homonegativity was described differently at various stages of the life course. When recounting their childhoods and early adolescence, participants described varied levels of experienced homonegativity within their families of origin, which was heavily influenced by conservative Christian religious environments. These experiences translated into anticipated and internalized homonegativity as participants went through adolescence and the accompanying processes of sexual identity formation and coming out. Finally, in describing more recent experiences in young adulthood, many participants discussed the impact of migration from stifling environments and the role of extrafamilial social support in their evolving self-acceptance.

Table 1 Participant demographics $(\mathrm{n}=28)$

\begin{tabular}{ll}
\hline Age & \\
Mean age & $24.3 \pm 2.7$ \\
Ethnicity: n (\%) & \\
African-American & $26(92.9 \%)$ \\
African-American/Latino & $1(3.6 \%)$ \\
African-American/American Indian & $1(3.6 \%)$ \\
Annual income: $\mathrm{n}(\%)$ & \\
$\mathrm{x}<20,000$ & $16(57.1 \%)$ \\
$20,000<\mathrm{x}<40,000$ & $8(28.6 \%)$ \\
$40,000<\mathrm{x}<60,000$ & $3(10.7 \%)$ \\
Not reported & $1(3.6 \%)$ \\
Education level: $\mathrm{n}(\%)$ & \\
High school diploma/GED & $8(28.6 \%)$ \\
Trade certification & $1(3.6 \%)$ \\
Some college & $13(46.4 \%)$ \\
Associate degree & $2(7.1 \%)$ \\
Bachelor's degree & $4(14.3 \%)$ \\
Daily medication adherence & \\
Yes & $23(82.1 \%)$ \\
No & $5(17.9 \%)$ \\
From the South & \\
Yes & $22(78.6 \%)$ \\
No & $6(21.4 \%)$ \\
Yrom Atlanta & \\
No & $20(71.4 \%)$ \\
\hline &
\end{tabular}

\section{Childhood and Early Adolescence: Experienced Homonegativity}

\section{Familial Homonegativity}

Many participants experienced homonegativity from their families of origin during childhood and early adolescence. Most were taught explicitly that being attracted to men or having sex with men was wrong; these messages were primarily framed with religious teachings.

We're very religious. Um, I started dating and talking to guys around 14. I tried to keep it under wraps, but my parents found out when I was 16 . We didn't do the whole conversion therapy $[\ldots]$ but they had their own little version where they took me out of the school activities. I was in church $24 / 7$, as much as possible. Took my cellphone, couldn't talk to anybody. They monitored the music I listened to, the TV shows that I watched. And they also had me talk to an elder, who is an ex-homosexual, who was married with kids. I had to talk to him for about an hour once a week for like, almost a year. And, uh, I mean, I'm still gay, so I'm like, you see how that went over (laughter). I'm not really close to my family like that because of that. (Participant 6, Age 27, Virginia).

In addition to these explicit messages about the immorality of same-sex sexual behaviors, participants also received negative communication about feminine gender expression. Many parents discouraged behaviors that could be perceived as gay or feminine, as illustrated below:

I told my dad, 'Hey, I think I like guys,' and my father's response was, 'I don't care what you do in your life, I don't care who you sleep with, just as not as you're not a bitch.' Those were his verbatim words and, you know, I just accepted it for what it was. [...] He didn't want me to be a flaming-ass gay, walking around I guess in high heels and wigs, and all the extra-ness that comes with this lifestyle that you typically will see. (Participant 4, Age 29, Virginia)

These participants' experiences of homonegativity in their home environments were representative of the majority of participants in our study.

\section{Escalation to Abuse and Trauma}

Trauma and abuse were common, with the majority of participants reporting verbal, emotional and/or physical abuse associated with their sexual orientation. Participant 7 related an incident in which his parents discovered him using their desktop computer to view pornographic images of men: 
My father just sat there looking at the picture [...] a dick on the screen and just looking at me. "This the type of shit you're doing?" My mom came in and picked up the chair and swung it at me. And then walked up, picked up the chair and proceeded to knock me over the head with the chair... [My mom] said she wishes that... like if that's the life that I choose she wishes that she would have had an abortion. (Participant 7, Age 27, Georgia)

Other participants specified the physical and mental health implications of such abuse and homonegativity. Below, one young man explained an encounter with his parents after he disclosed to them that had been raped by his older brother:

My father would call [me] a liar [...] I remember the first time it happened, I was bleeding, and it hurt really bad and I showed my mother and my mother shows my father. And my dad says that's, he probably hurt himself. And my mother told me, "Did you hurt yourself?" I said, "No, [my brother] did this to me." And he says to me, "My son isn't a faggot. You're not a faggot. Stop pretending that you are!" [...] I grew very angry, very angry to the point where I grew hate in my heart for life. (Participant 21, Age 28, New Jersey)

These descriptions of abuse were the most extreme manifestations of familial homonegativity, but they were not uncommon in our sample.

\section{Variation in Familial Homonegativity}

Of note, a minority of participants had families that were generally accepting of their sexuality, as illustrated below:

[My sexuality] was never frowned upon, but it was just kind of looked at in the family as okay, he's a little different. It's okay, we still love you, you're a little sweet around the edges... But it was never frowned upon, it was never looked at as a bad thing, I was never bullied about it, I was never talked badly about. (Participant 13, Age 25, Metropolitan Atlanta)

Additionally, even for those who experienced some form of familial homonegativity, it is important to note that such views were rarely held or expressed by the entire family. While some family members served as a source of stigma; others often provided support. Participant 12 gives an example of this phenomenon.

My mother kicked me out the house on [specific date]; I have not stayed in the same household with my mom since that day. We've been in the same space, but I've never lived or laid my head down in the same house with her because I was so hurt that you kicked me out.
The reason she kicked me out was because, I remember that day so vaguely, she said, "What's this I hear you sucking niggas' dicks and giving them your money?" So, I just grabbed a few belongings, and I took the car that they had got me, and I remember the next day they came to the school and took my car. Child, they took my car and cut my cellphone off. So, my aunt gave me her [make and model of car]. (Participant 12, Age 25, Arkansas)

Although this participant was recounting a very painful memory of non-acceptance from his mother, the story ultimately ended with an aunt who was willing to provide the missing support.

\section{Sexual Identity Formation and Coming Out: Internalized and Anticipated Homonegativity}

Some participants explicitly outlined pathways between experienced homonegativity earlier in life, and subsequent internalization of homonegativity and accompanying psychological distress during the processes of sexual identity formation and coming out.

Of course, growing up in a religious household and being a preacher's kid, I was - my sexuality became a point of contention when I was like 14, 15. And it had me thinking very badly of myself. That's the part where the self-love didn't really get instilled because it's like you're told [being gay] is an abomination and you're going to go to hell. So, I'm thinking, I'm sitting here praying to God every night, to take it away, crying myself to sleep, doing everything in the book and watching straight porn, doing everything and trying to make myself go straight...just like pretty much just tearing myself apart. (Participant 6, Age 27, Virginia)

The theme of religion and the church was pervasive in discussions of internalized homonegativity — as much of the internal conflict participants described seemed to stem from attempts to reconcile religious teachings with their growing self-awareness of their sexuality. The quote below further details this quandary and conflicted relationship with the church:

I always went to church every Sunday, every Monday, every Wednesday, and every Friday. Church was a good experience, but the church I was going to was starting to be a little bit too much and it was just like, with me being gay and stuff [...] like I know what the 
Bible says. I know what it means but that's not the only thing in the Bible you know, and I felt like it was just the more I was getting older, I felt like it was more apparent that I was gay and I felt like those were the messages that were kept getting spoken about. It's just like, I don't think I want to go to this church. (Participant 15, Age 20, Florida)

Many participants also described ways in which anticipated homonegativity led them to explore their sexual attraction for men in secret, including a system of "code switching" in which they de-emphasized their gay identity when with their family or members of their religious community as illustrated below:

[I was] not comfortable with my church members until I was older and in college and then those church members that were on my Facebook page [...] like my gay friends commenting on stuff and you know because sometimes my gay friends used a lot more [Black gay] lingo than I ever did when I first got to college. So, like 'the girl,' 'the bitch,' like I didn't do all of that. So, when they would comment [on my Facebook page] and call me girl, I'm like, 'Delete that! What is wrong with you? My pastor is on my Facebook. Like no!' (Participant 3, Age 25, Texas)

This type of cognitive dissonance was described by many participants during their sexual identity formation processes and was sometimes associated with social isolation and depression.

\section{Pathways Between Homonegativity and HIV Risk}

Participants explicitly described two ways in which homonegativity contributed to their HIV risk: through lack of education and awareness and through forced secrecy about their sexuality, leading to high-risk sexual encounters. Additional consequences of homonegativity with potential implications for HIV risk include psychological distress and housing instability.

\section{Lack of Sexual Health Education}

Some of our participants made explicit connections between homonegative environments and their eventual risk for, and acquisition of, HIV. Looking retrospectively at their childhoods and early adolescent stages, many participants associated homonegativity in their families and communities with missed opportunities for vital sexual education. Many participants expressed regret about not having knowledge of
HIV prevention methods prior to their diagnosis and cited this information gap as a contributor to their subsequent risk for HIV, as illustrated below:

When I was 14, I started to become sexually active. And I guess because that was such, like, a hard time for me in life, I kind of sought out to sex and guys and kind of like partying as a way to escape reality [...] I knew no knowledge of sex at all, like I didn't know how to prepare, what to do. I knew nothing about HIV, STDs, like, anything, because it was at a point where I was so distant away from everyone [in my family] that I didn't have anyone to kind of tell me about anything. (Participant 8, Age 18, Metropolitan Atlanta)

These comments echoed sentiments that were voiced by the majority of our participants, illustrating the ways in which families and school systems may fail to provide necessary sexual education during early adolescence, particularly for sexual minority youth.

\section{Secrecy Leading to High-Risk Behaviors}

Secrecy about same-sex encounters and behaviors, prompted by familial homonegativity, contributed to increased risk behavior among participants and many participants acknowledged it as a facilitator of contracting HIV.

Just in the sense honestly having HIV for the last, Jesus, no wait... 5 years [...] I kind of initially felt like I disappointed myself. Like I let myself down, like I let my family down just because of the bad [sexual] decisions that I made to get me to the point that I am now [...] when I was in high school [my mom and I] bickered and fought a lot. I got caught doing dumb stuff all of the time like sneaking people in the house and like sneaking out of the house or staying out past curfew or getting caught being at the club. (Participant 24, Age 23, Connecticut)

In addition to these direct effects on sexual behavior, many also described ways in which homonegative environments led to known HIV risk factors such as psychological distress (discussed above) and housing instability. Forced displacement, or being "kicked out", was described by several participants and often led to social isolation, homelessness, and financial struggles, as described below.

May of 2015, I was negative. When I was homeless, I slept from, I slept with one person to the next to the next to the next, performing oral sex or sleeping just to be able to have a place to sleep for that night so that I wouldn't be out in the rain or out walking the streets late at night. Very few times was penetration involved. It was more so...it was more so oral and [inaudible]. And 
I needed to get tested again and I went the week right before Thanksgiving. [I found out I had HIV] the Friday right before Thanksgiving of [specific year]. (Participant 5, Age 24, Metropolitan Atlanta)

Because of the possibility of being disowned, another participant described waiting until he secured a degree, a job, and secure place to live before he came out to his family. These stories illustrate the material consequences that were often associated with disclosing sexuality to close family members, highlighting both experienced and anticipated homonegativity in our participants' lives.

\section{Evolving Self-Acceptance}

In spite of the pervasive homonegativity and its consequences, most of our participants described eventual self-acceptance of both sexuality and HIV status. For many, this process was framed within a physical move to Atlanta from other parts of the South. Participants highlighted the importance of new social support networks in mitigating the effects of prior homonegativity.

\section{Accepting Gay Sexuality and HIV Status}

Internalized homonegativity was discussed primarily in the past tense, as a phase to outgrow. Confident expressions of gay sexuality were common, exemplified below:

At this point I'm grown, so I will tell anybody if they ask. I am not ashamed of who I am. When I was younger, I would probably be very cautious about it, but now I'm like if you wanna know, I am going to tell you. That is one thing, I am not going to be ashamed of. (Participant 26, Age 24, South Carolina)

HIV seroconversion required a second self-acceptance process in addition to the ongoing struggles of accepting one's gay identity. In most participants, the sexual identity acceptance process and HIV status acceptance process were sequential; for others they were concurrent and intimately intertwined. Some participants expressed that, over time, their negative feelings about their HIV status waned-mirroring the trajectory of their feelings about their sexual identities (i.e. decreasing internalized homonegativity).

\section{Autonomy and Migration from Stifling Environments}

As our participants entered young adulthood, they began to have the agency to leave stifling home and church environments. This separation was often a conscious decision made in the interest of self-preservation, as described below:
I think it's difficult for me to see my sexuality intertwine in other environments that are expressively against who I am [...] I don't like being in environments that are not conducive to me, that hate me and don't want me there [...] that's why I don't often see myself in a church or in environments of faith or pious people because my wellbeing is important to me. (Participant 18, Age 22, Metropolitan Atlanta)

As noted above, most participants were not raised in Atlanta. Many young men spoke about how moving away from their childhood home, to Atlanta, was a "freeing" experience in terms of gay identity and expression. The quotation below illustrates this sentiment:

Back in Florida, I wasn't confident at all because I couldn't be my true self, so when I moved to Atlanta, I was like okay, I got the gratification, like this is real. I'm comfortable with me, this is my true self. And I couldn't do that in Florida until I started, you know, moved here and [saw] everyone - okay, he's walking around in heels and makeup, that's his true, authentic self. So, this is going to be mine. You know, I'm cool with that, I'm comfortable with it. (Participant 11, Age 27, Florida)

Once autonomous in Atlanta, the discovery of identityaffirming spaces (e.g., support groups for gay men living with HIV, gay nightclubs) was described as being vital to the self-acceptance process and overall health and well-being. In these spaces, participants asserted that they were able to find support in the form of friends and mentors: "Being around other gay people who are comfortable with their sexuality. It's like a confidence booster." (Participant 2, Age 23, Georgia).

\section{Discussion}

Experienced, anticipated and internalized homonegativity were pervasive as YB-GBMSM navigated family and religious environments over the life course. Through our analysis, we found that these stifling, sometimes traumatic, environments encountered during childhood and early adolescence were often associated with experienced homonegativity. This in turn led to internalized and anticipated homonegativity that shaped sexual identity formation and expression in middle adolescence and young adulthood. Through physical separation from homonegative environments, often involving migration to Atlanta from other parts of the South, most participants had reached some level of self-acceptance of their sexuality and HIV status by the time of their interview. A key factor in reaching self-acceptance was the presence of social support 
(from family of origin and/or new networks) in the lives of participants.

Our participants had complicated and varied relationships with their families of origin and often described the role of friends or mentors in providing support that was missing. These complex support structures echo the concepts of families of choice for LGBTQ individuals [26] or fictive kin more commonly discussed in Black populations [27]. A recent study outlined different typologies of "family" for young GBMSM in Detroit, highlighting the outsized role of individuals with no biological or legal ties in providing family-type support [28]. In this study, it was notable that nearly $90 \%$ of their participants included families of origin in their definition of family (even if others such as friends or partners were included as well). These findings are similar to our study, in which most participants did not describe complete alienation-but discussed significant tensions in navigating familial relationships from which they derived varying levels of support around their sexual orientation. Thus, when conceptualizing YB-GBMSM families and support networks for intervention development or direct care, it seems prudent to include the family of origin — but to also be inclusive of a wide range of "family" structures, support networks and dynamics.

Religious themes were pervasive in participants' descriptions of the homonegativity they encountered and internalized, reflecting high levels of religiosity among Black Americans, particularly in the South-where most of our participants were raised. Our participants' complicated relationship with religious environments is consistent with other studies of religiosity among Black GBMSM [11, 13, 29]; acknowledging both the importance and potentially harmful effects of the church in their lives. Given the importance of Black churches in the community, and the importance of religion to YB-GBMSM themselves, approaches to decrease homonegativity in the church are of paramount importance. We concur with public health leaders who suggest that instead of simply helping YB-GBMSM to cope with homonegativity from the church, public health practitioners should engage with church leadership to develop productive approaches to decreasing stigma while promoting tolerance and compassion within the church [30]. Proposed approaches include the provision of HIV testing services within congregations through special ministries and using scripture within religious spaces to directly denounce homophobia and teach acceptance [29].

Our participants' trajectories of sexual identity realization culminating in eventual acceptance (for most) were consistent with — but also added to- - existing frameworks for understanding sexual identity formation among LGBTQ youth (e.g., Troiden's Model of Sexual Identity and Development, Coleman's Developmental Stages of the Coming Out Process, and the Cass Identity Model) [31-33]. These existing models, which describe the sexual identity development process of LGBTQ youth, begin with a stage characterized by confusion and feelings of marginalization and end with identity synthesis that involves acceptance of one's sexuality [31-33]. Our analysis adds further context to understanding of these stages among YB-GBMSM living with HIV in Atlanta, whose sexual identity formation processes were shaped by specific cultural contexts, including a heavy influence of religion. Instead of the "generalized feelings of marginality" based on difference from heterosexual peers described in existing sexual identity models, the feelings of YB-GBMSM additionally stem from not fitting into racial, gendered, and sexual expectations of black families and churches.

The associations between homonegative environments during adolescence and HIV risk demonstrated in the data adds to the existing body of knowledge on the relationships between homonegativity, environment, and health outcomes among Black GBMSM [19, 34-37]. Internalized homonegativity is mainly thought to negatively impact the physical and mental health of this population through pathways in which psychological distress leads to individual-level risk. Our participants' narratives outlined another pathway between early experienced homonegativity and later HIV risk, mediated by suboptimal sexual education. Participants blamed parents, school systems and the church for lack of discussion of same-sex sexual behaviors, postulating that such education might have prevented their eventual HIV seroconversion. These narratives support calls for comprehensive sexual education that is inclusive of same-sex behaviors-both in families and in other (e.g., school-based) settings. HIVrelated sexual health information has been cited as a human right by the United Nations [38] — but is severely restricted in many US schools due to state-level policies, particularly those in the South [39].

Our interviews suggest that increased physical and emotional distance from homonegative environments may play a crucial part in reaching self-acceptance among YBGBMSM. The majority of participants migrated to Atlanta from out-of-state, but the theme of migration was not limited to this particular trajectory. Even within Atlanta, simply leaving the parental home could similarly facilitate the self-acceptance process. In these newfound environments, our participants were able to gain social support through new connections, and participants often discussed the idea that new relationships with similar individuals (age, sexual orientation, and HIV serostatus) can bolster selfconfidence, coping skills, and engagement in HIV care. Our findings are consistent with a prior study which found that increased internalized homonegativity was linked to decreased likelihood that a gay man had been in a gay social space, such as a club or sexual minority serving organization [12]. A number of researchers have examined 
the importance and influence of identity-affirming environments for GBMSM more generally [11-13]. Future interventions could aim to facilitate social support within identity-affirming spaces, similar to what many participants discovered organically over their life course.

\section{Limitations}

This study had several limitations. As participants had to self-report HIV-positive status and gay sexual identity to screen into the study, there may have been a selection bias towards those who are further along in these selfacceptance processes. Additional selection bias may have resulted from the fact that much of our recruitment happened through an HIV clinic-YB-GBMSM who were engaged in care there may have overall had more stable life situations than those who are out of care. Finally, this was a one-time, cross-sectional study of dynamic processes, and we acknowledge that we may not have fully captured the complex trajectories of our participants' journeys towards self-acceptance.

\section{Conclusions}

Homonegativity experienced over the life course of YBGBMSM living with HIV has critically important public health implications related to prevention and treatment of HIV. Our analysis suggests that early experiences of homonegativity in the church and home lead to further internalized and anticipated homonegativity, with significant implications for HIV risk and general mental health. Our participants dealt with these stressors at times by moving to (or within) Atlanta to distance themselves from harmful environments, which had both beneficial and harmful effects. Future work in this area should focus on improving sex education, working with families and churches, and providing social support in identity-affirming spaces for YB-GBMSM in the South.

Acknowledgements This study was supported by the Centers for Disease Control and Prevention (U01 PS005112) and the Center for AIDS Research at Emory University (P30AI050409).

\section{Compliance with Ethical Standards}

Conflict of interest All authors declare that they have no conflicts of interest.

Ethical Approval All procedures performed in studies involving human participants were in accordance with the ethical standards of the insti- tutional and/or national research committee (Emory IRB and Grady Research Oversight Committee) and with the 1964 Helsinki declaration and its later amendments or comparable ethical standards.

Informed Consents Informed consent was obtained from all individual participants included in the study.

\section{References}

1. Centres for Disease Control and Prevention. CDC-HIV in the United States-Statistics Overview-Statistics Center-HIV/ AIDS. HIV in the United States: At A Glance. 2017.

2. Wejnert C, Hess KL, Rose CE, Balaji A, Smith JC, Paz-Bailey G, et al. Age-specific race and ethnicity disparities in hiv infection and awareness among men who have sex with men-20 US cities, 2008-2014. J Infect Dis. 2016;213(5):776-83.

3. Centers for Disease Control and Prevention. HIV in the United States by Geography. CDC. 2017.

4. Prevention C for DC and. HIV in the Southern United States. 2016.

5. Adimora AA, Ramirez C, Schoenbach VJ, Cohen MS. Policies and politics that promote HIV infection in the Southern United States. AIDS. 2014.

6. Reif SS, Whetten K, Wilson ER, McAllaster C, Pence BW, Legrand S, et al. HIV/AIDS in the Southern USA: a disproportionate epidemic. AIDS Care-Psychol Socio-Medical Asp AIDS/ HIV. 2014.

7. Gray SC, Massaro T, Chen I, Edholm CJ, Grotheer R, Zheng Y, et al. A county-level analysis of persons living with HIV in the southern United States. AIDS Care. 2016;28(2):266-72.

8. Ligtenberg SRM, Helsen MM, van den Broeke MR. An improved semi-empirical model for the densification of Antarctic firn. Cryosphere. 2011;5(4):809-19.

9. Meyer IH. Prejudice, social stress, and mental health in lesbian, gay, and bisexual populations: conceptual issues and research evidence. Psychol Bull. 2003;129(5):674.

10. Bauermeister JA, Johns MM, Sandfort TGM, Eisenberg A, Grossman AH, D'Augelli AR. Relationship trajectories and psychological well-being among sexual minority youth. J Youth Adolesc. 2010;39(10):1148-63.

11. Balaji AB, Oster AM, Viall AH, Heffelfinger JD, Mena LA, Toledo CA. Role flexing: how community, religion, and family shape the experiences of young black men who have sex with men. AIDS Patient Care STDS. 2012;26(12):730-7.

12. Berg RC, Weatherburn P, Ross MW, Schmidt AJ. The relationship of internalized homonegativity to sexual health and well-being among men in 38 European countries who have sex with men. $\mathbf{J}$ Gay Lesbian Mental Health. 2015;19(3):285-302.

13. Quinn K, Dickson-Gomez J, DiFranceisco W, Kelly JA, St. Lawrence JS, Amirkhanian YA, Broaddus M. Correlates of internalized homonegativity among black men who have sex with men. AIDS Educ Prev. 2015;27(3):212-26.

14. Smallwood SW, Spencer SM, Ingram LA, Thrasher JF, Thompson-Robinson MV. Different dimensions: internalized homonegativity among African American men who have sex with men in the Deep South. J Homosex. 2017;64(1):45-60.

15. Shoptaw S, Weiss RE, Munjas B, Hucks-Ortiz C, Young SD, Larkins $\mathrm{S}$, et al. Homonegativity, substance use, sexual risk behaviors, and HIV status in poor and ethnic men who have sex with men in Los Angeles. J Urban Health. 2009;86(S1):77-92.

16. Jeffries WL, Johnson OD. Homonegative attitudes and risk behaviors for HIV and other sexually transmitted infections among 
sexually active men in the United States. Am J Public Health. 2015;105(12):2466-72.

17. Jeffries WL IV, Marks G, Lauby J, Murrill CS, Millett GA. Homophobia is associated with sexual behavior that increases risk of acquiring and transmitting HIV infection among black men who have sex with men. AIDS Behav. 2013;17(4):1442-53.

18. Jeffries WL, Gelaude DJ, Torrone EA, Gasiorowicz M, Oster AM, Spikes PS, et al. Unhealthy environments, unhealthy consequences: experienced homonegativity and HIV infection risk among young men who have sex with men. Glob Public Health. 2017;12(1):116-29.

19. Geter A, Ricks JM, McGladrey M, Crosby RA, Mena LA, Ottmar JM. Experiences of antihomosexual attitudes and young black men who have sex with men in the south: a need for communitybased interventions. LGBT Health. 2016;3(3):214-8.

20. Bartone MD. "Nothing has stopped me. I keep going:” Black gay narratives. J LGBT Youth. 2017;14(3):317-29.

21. Sullivan PS. AIDSVu: an interactive online surveillance mapping resource to improve HIV prevention in the US. In: Medicine 20 Conference. 2013.

22. Kelley CF, Vaughan AS, Luisi N, Sanchez TH, Salazar LF, Frew $\mathrm{PM}$, et al. The effect of high rates of bacterial sexually transmitted infections on HIV incidence in a cohort of black and white men who have sex with men in Atlanta, Georgia. AIDS Res Hum Retrovir. 2015;31(6):587-92.

23. Hussen SA, Jones M, Moore S, Hood J, Smith JC, Camacho-Gonzalez AF, et al. brothers building brothers by breaking barriers: development of a resilience-building social capital intervention for young black gay and bisexual men living with HIV. AIDS Care. 2018;30(sup4):51-8.

24. Hennink M, Hutter I, Bailey A. Qualitative research methods. Sage; 2010.

25. Charmaz K. Constructing grounded theory: a practical guide through qualitative analysis. Sage; 2006.

26. Weston K. Families we choose: lesbians, gays, kinship. Columbia University Press, New York; 1991. 26 p.

27. Chatters LM, Joseph TR, Jayakody R. Fictive kinship relations in black extended families. J Comp Family Stud. 1994;25:297-312.

28. Soler JH, Caldwell CH, Córdova D, Harper G, Bauermeister JA. Who counts as family? Family typologies, family support, and family undermining among young adult gay and bisexual men. Sex Res Soc Policy. 2018;15(2):123-38.
29. Jeffries WL, Okeke JO, Gelaude DJ, Torrone EA, Gasiorowicz M, Oster AM, et al. An exploration of religion and spirituality among young, HIV-infected gay and bisexual men in the USA. Cult Health Sex. 2014;16(9):1070-83.

30. Jeffries WL IV, Sutton MY, Eke AN. On the Battlefield: the black church, public health, and the fight against HIV among African American gay and bisexual men. J Urban Health. 2017;94(3):384-98.

31. Coleman E. Developmental stages of the coming-out process. J Homosex. 1982;7(2-3):31-43.

32. Cass VC. Homosexual identity formation: testing a theoretical model. J Sex Res. 1984;20(2):143-67.

33. Troiden RR. Homosexual identity development. J Adolesc Health Care. 1988;9(2):105-13.

34. Fields EL, Bogart LM, Smith KC, Malebranche DJ, Ellen J, Schuster MA. "I always felt I had to prove my manhood": homosexuality, masculinity, gender role strain, and HIV risk among young black men who have sex with men. Am J Public Health. 2015;105(1):122-31.

35. Graham LF, Aronson RE, Nichols T, Stephens CF, Rhodes SD. Factors influencing depression and anxiety among black sexual minority men. Depress Res Treat. 2011;2011:587984.

36. White D, Stephenson R. Identity formation, outness, and sexual risk among gay and bisexual men. Am J Mens Health. 2014;8(2):98-109.

37. Malebranche DJ, Fields EL, Bryant LO, Harper SR. Masculine socialization and sexual risk behaviors among Black men who have sex with men: a qualitative exploration. Men Masc. 2009;12(1):90-112.

38. Santelli JS, Kantor LM, Grilo SA, Speizer IS, Lindberg LD, Heitel J, et al. Abstinence-only-until-marriage: an updated review of US policies and programs and their impact. J Adolesc Health. 2017;61(3):273-80.

39. Elliot LM, Booth MM, Patterson G, Althoff M, Bush CK, Dery MA. Association of state-mandated abstinence-only sexuality education with rates of adolescent HIV infection and teenage pregnancy. J La State Med Soc. 2017;169(2):56.

Publisher's Note Springer Nature remains neutral with regard to jurisdictional claims in published maps and institutional affiliations. 